\title{
Infarcts in the territory of the lateral branch of the posterior inferior cerebellar artery
}

\author{
A Barth, J Bogousslavsky, F Regli
}

\begin{abstract}
The territory of the lateral branch of the posterior inferior cerebellar artery (1PICA) supplies the anterolateral region of the caudal part of the cerebellar hemisphere. Because infarcts in the territory of the 1PICA have rarely been studied specifically, 10 patients with this type of infarct are reported. An 1PICA infarct was isolated in only three patients, whereas it was associated with brainstem infarct in four, with occipital infarct in one, and with multiple infarcts in two patients. The most common symptom at onset was acute unsteadiness and gait ataxia without rotatory vertigo (six patients). Unilateral cerebellar dysfunction was found in all patients, with limb ataxia (nine patients), dysdiadochokinesia (five patients), and ipsilateral body sway (four patients), but dysarthria and primary position nystagmus were notably absent. In the patients with a coexisting infarct in the brainstem, cranial nerve and sensorimotor dysfunction was prominent and often masked the signs of cerebellar dysfunction. Unlike other infarcts in the PICA territory, 1PICA territory infarcts were mainly associated with vertebral artery atherosclerosis (six patients), whereas cardiac embolism was less common (three patients). Unilateral limb ataxia without dysarthria or vestibular signs suggests isolated IPICA territory infarction and should allow its differentiation from other cerebellar infarcts.
\end{abstract}

$(尹$ Neurol Neurosurg Psychiatry 1994;57:1073-1076)

Cerebellar infarcts in the territory of the lateral branch of the posterior inferior cerebellar artery (1PICA) have rarely been reported. A few pathological findings and one clinical report exist. ${ }^{1-3}$ We had the opportunity to study 10 patients with an infarct in the 1PICA territory documented on MRI. This allowed us to delineate suggestive clinical features and to evaluate the potential causes of infarcts in the 1PICA territory.

Patients and methods

Ten patients (two women aged 77 and 81 years; eight men, mean age 64 (SD 10) years) were selected from the Lausanne Stroke Registry between 1988 and 1992. The characteristics of this registry, which records information on first ever stroke patients consecutively admitted to a population based primary care centre, have been reported. ${ }^{4}$

All patients had had the systematic investigations of the registry (CT, Doppler sonography, ECG, 3-lead ECG monitoring for at least 24 hours, standard blood tests). Conventional cerebral angiography was performed in one patient and echocardiography in four patients. MRI was performed in all patients with a Siemens Magneton 63 SP 1.5 tesla between three and seven days after stroke. The MRI studies included T1, T2, and proton weighted images. MR angiography of the vertebral and basilar arteries was performed in eight patients and consisted of a three dimensional time of flight sequence sensitive to arterial flow with saturation of the veins (TR $36 \mathrm{~ms}$, TE $7 \mathrm{~ms}$, FA 15 $5^{\circ}, 64$ slices of 0.8 to $1 \mathrm{~mm}$ ). The angiographic data were reconstructed with a multiple intensity projection algorithm and displayed in three dimensions.

The lateral branch territory of the PICA was determined on MRI after recent anatomical and pathological studies. ${ }^{56}$ The PICA arises from the end portion of the vertebral artery and supplies the caudal part of the cerebellar hemisphere and vermis, as well as the dorsolateral region of the medulla oblongata. It divides into two main branches: (a) The medial branch (mPICA), which supplies the dorsomedial part of the cerebellar PICA territory and the dorsal medullary territory; $(b)$ the lateral branch (1PICA), which supplies the anterolateral part of the cerebellar PICA territory (fig 1).

Because of possible variations of the PICA calibre and the possible supply of its lateral territory by the anterior inferior cerebellar artery (AICA) in $13 \% \%^{6}$ to $40 \%{ }^{7}$ of the population, we considered a diagnosis of infarct in
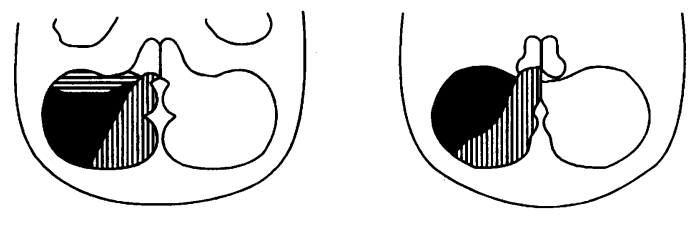

A Barth

J Bogousslavsky

F Regli

Correspondence to:

Department of Neurology,

Centre Hospitalier

Universitaire Vaudois,

Switzerland.

Received 18 October 1993

and in revised form

11 February 1994

Accepted 18 February 1994 
Figure 2 Topography of IPICA territory infarcts in 10 patients.
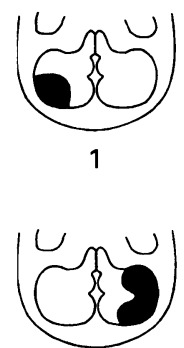

4

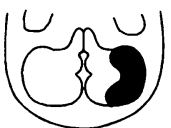

7
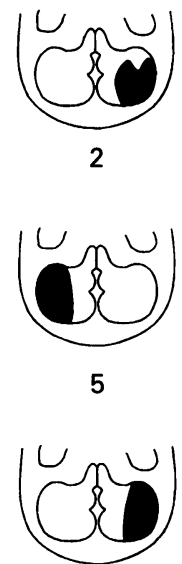

8

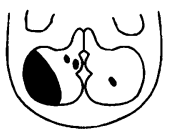

10
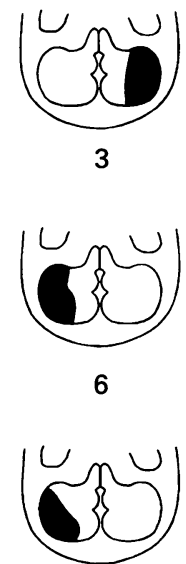

9 the 1PICA territory oned the middle cerebellar peduncle and the flocculus, which are classically supplied by the AICA.

Results (figure 2)

Among 10 patients, only three had an isolated infarct in the 1PICA territory. Seven patients had associated infarcts: four in the brainstem, one occipital, and two multiple (supratentorial and infratentorial). The 1PICA territory infarcts were equally distributed on the right and left side. They were never bilateral. Figure 3 gives an example of an 1PICA territory infarct on MRI.
CLINICAL FEATURES

The most common symptom at onset was axial unsteadiness without rotatory vertigo, being present in six patients including all three with isolated 1PICA territory infarcts. In these patients, stroke onset was typically subacute with symptoms progressing over several hours. Acute rotatory vertigo was present at onset in three patients, all of whom had associated infarct(s) in the brainstem. One patient with a concomitant pontine infarct presented with diplopia and hemiparesis. Dysarthria, nausea and vomiting, and headaches were present only in patients with associated infarcts. All patients had pronounced signs of cerebellar dysfunction with ipsilateral limb ataxia in nine patients (defined as movements with irregular accelerations and decelerations producing oscillations on getting close to the target on the finger to nose and heel to knee tests $\left.^{8}\right)$. Limb ataxia involved arms and legs to the same extent. Dysdiadochokinesia was present in five patients and ipsilateral body sway in four. There was no case with primary position nystagmus. Multidirectional gaze evoked nystagmus was present in five patients, always in association with other infarcts. In all four patients with a coexisting infarct in the brainstem, cranial nerve and sensorimotor dysfunction was prominent and often masked the signs of cerebellar dysfunction. The table summarises these data.

\section{CAUSES OF STROKE}

Arterial hypertension (six patients) and cigarette smoking (four patients) were the most frequent risk factors. Two patients had fasting hypercholesterolaemia. Only one patient had chronic non-valvar atrial fibrillation. No patients had diabetes mellitus.

Local atherosclerosis with narrowing of the
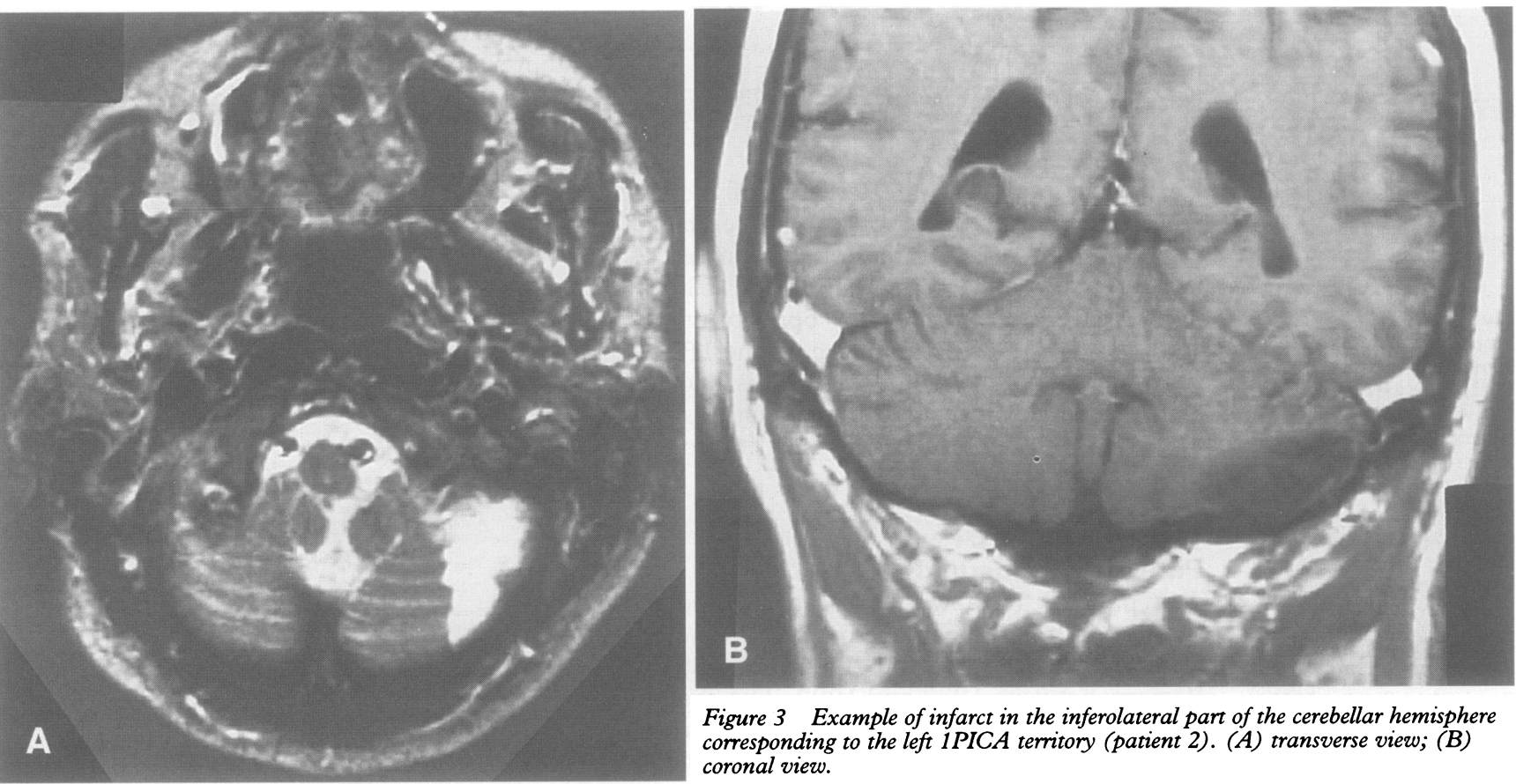

Figure 3 Example of infarct in the inferolateral part of the cerebellar hemisphere corresponding to the left 1PICA territory (patient 2). (A) transverse view; (B) coronal view. 
Clinical patterns of 10 patients with IPICA territory infarct

\begin{tabular}{|c|c|c|c|c|c|}
\hline $\begin{array}{l}\text { Patient/age/ } \\
\text { sex }\end{array}$ & Other infarcts & Symptoms & Signs & Causes & Risk factors \\
\hline $1 / 71 / M$ & 0 & Unsteadiness & $\begin{array}{l}\text { Limb ataxia with } \\
\text { dysmetria, ipsilateral } \\
\text { axial lateropulsion }\end{array}$ & Atherosclerosis & Hypertension \\
\hline $2 / 60 / \mathrm{M}$ & 0 & Unsteadiness & $\begin{array}{l}\text { Limb ataxia with } \\
\text { dysmetria, ipsilateral } \\
\text { axial lateropulsion }\end{array}$ & Cardioembolism & $\begin{array}{l}\text { Ventricular } \\
\text { dyskinesia }\end{array}$ \\
\hline $3 / 77 / \mathrm{F}$ & 0 & Unsteadiness & $\begin{array}{l}\text { Limb ataxia with } \\
\text { dysmetria }\end{array}$ & Cardioembolism & $\begin{array}{l}\text { Atrial } \\
\text { fibrillation }\end{array}$ \\
\hline 4/69/M & $\begin{array}{l}\text { Midbrain } \\
\text { (acute) }\end{array}$ & $\begin{array}{l}\text { Vertigo, dysarthria, } \\
\text { diplopia, facial } \\
\text { paresthesiae }\end{array}$ & $\begin{array}{l}\text { Limb ataxia, hemiparesis, } \\
\text { vertical nystagmus, } \\
\text { upward gaze palsy }\end{array}$ & Atherosclerosis & 0 \\
\hline $5 / 51 / M$ & $\begin{array}{l}\text { Pons } \\
\text { (acute) }\end{array}$ & $\begin{array}{l}\text { Vertigo, } \\
\text { unsteadiness, } \\
\text { limb paresthesiae }\end{array}$ & $\begin{array}{l}\text { Limb ataxia, nystagmus, } \\
\text { hypoacusis, hemiparesis }\end{array}$ & Arteritis & Smoking \\
\hline $6 / 65 / M$ & $\begin{array}{l}\text { Pons } \\
\text { (acute) }\end{array}$ & $\begin{array}{l}\text { Limb weakness, } \\
\text { diplopia, } \\
\text { dysarthria }\end{array}$ & $\begin{array}{l}\text { Limb ataxia, } \\
\text { hemiparesis, internuclear } \\
\text { ophthalmoplegia }\end{array}$ & Atherosclerosis & $\begin{array}{l}\text { Smoking } \\
\text { hypercholesterolaemia }\end{array}$ \\
\hline $7 / 46 / M$ & $\begin{array}{l}\text { Laterobulbar } \\
\text { (acute) }\end{array}$ & $\begin{array}{l}\text { Facial pain and } \\
\text { dysaesthesiae, } \\
\text { diplopia, vertigo }\end{array}$ & $\begin{array}{l}\text { Limb ataxia, ipsilateral } \\
\text { axial lateropulsion, } \\
\text { facial hypaesthesia, } \\
\text { nystagmus, skew deviation }\end{array}$ & Atherosclerosis & $\begin{array}{l}\text { Hypertension } \\
\text { smoking }\end{array}$ \\
\hline 8/72/M & $\begin{array}{l}\text { Temporo- } \\
\text { occipital } \\
\text { (acute) }\end{array}$ & $\begin{array}{l}\text { Unsteadiness, } \\
\text { short vertigo }\end{array}$ & $\begin{array}{l}\text { Limb ataxia, ipsilateral } \\
\text { axial lateropulsion, } \\
\text { gaze ataxia }\end{array}$ & Atherosclerosis & $\begin{array}{l}\text { Hypertension } \\
\text { smoking } \\
\text { hypercholesterolaemia }\end{array}$ \\
\hline 9/76/M & $\begin{array}{l}\text { Pons }+ \\
\text { occipital } \\
\text { (old) }\end{array}$ & $\begin{array}{l}\text { Unsteadiness, } \\
\text { blurred vision }\end{array}$ & $\begin{array}{l}\text { Limb ataxia with } \\
\text { dysmetria, trunk } \\
\text { ataxia, nystagmus }\end{array}$ & Cardioembolism & $\begin{array}{l}\text { Arythmia } \\
\text { hypertension }\end{array}$ \\
\hline $10 / 81 / \mathrm{F}$ & $\begin{array}{l}\text { Multiple } \\
\text { cerebellar }\end{array}$ & $\begin{array}{l}\text { Vertigo, nausea, } \\
\text { diplopia, } \\
\text { dysarthria }\end{array}$ & $\begin{array}{l}\text { Trunk ataxia, nystagmus, } \\
\text { facial nerve palsy, } \\
\text { hypoacusis }\end{array}$ & Atherosclerosis & Hypertension \\
\hline
\end{tabular}

ipsilateral distal (V3-V4) vertebral artery was the most frequent vascular pathology associated with 1PICA territory infarct (six patients). Local occlusion of the PICA was not visualised with certainty on MR angiographic sequences, probably because of current technical limitations (fig 4). Conventional angiography performed in one patient showed a proximal occlusion of the PICA associated with advanced atherosclerotic narrowings of the vertebrobasilar arteries. Three patients had a potential cardiac source of embolism (atrial fibrillation in one patient and

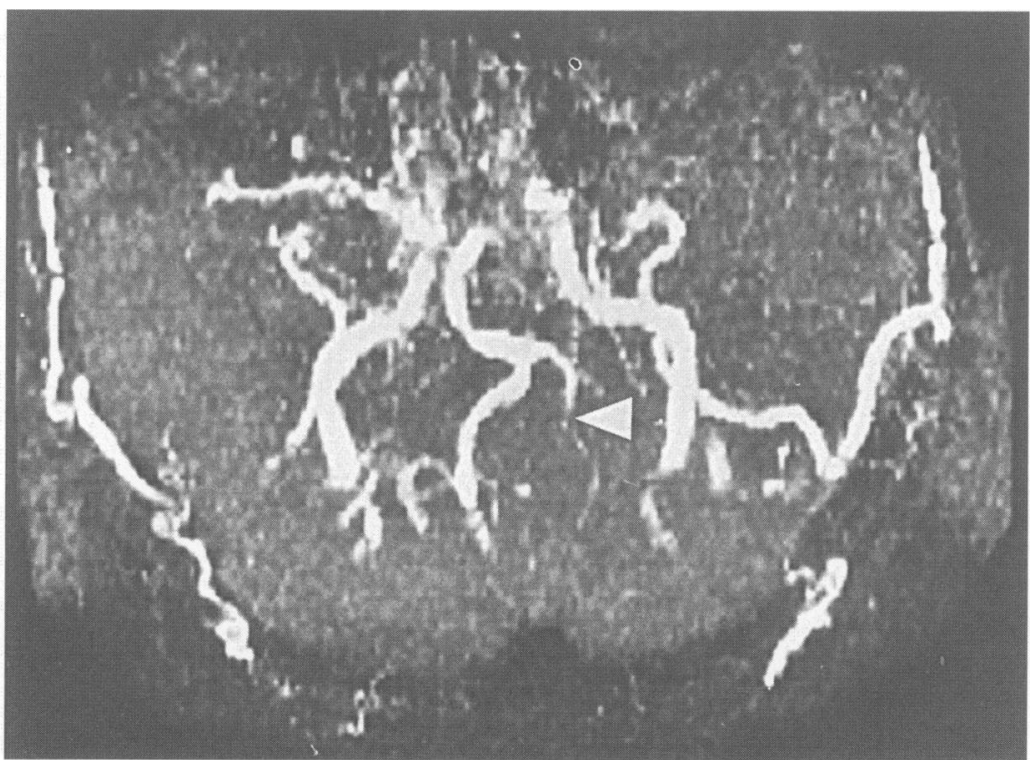

Figure $43 D$ coronal MR angiographic sequence showing a clearly reduced signal of the left intracranial vertebral artery (arrow head). The left PICA is not visible. In this hypertensive patient with infarction limited to the inferolateral territory of the left cerebellar hemisphere, MR angiography is compatible with distal vertebral artery disease and occlusion of the PICA (patient 1). left ventricular akinetic segment secondary to ischaemic heart disease in two patients). In another patient with an 1PICA territory infarct and distal vertebral artery thrombosis, IgM anticardiolipin antibodies were highly positive (40 MPL units).

EVOLUTION

In the three patients with an infarct limited to the IPICA territory, the evolution was favourable, with complete regression of the cerebellar dysfunction within one month after stroke. Four patients with associated brainstem infarct(s) only had partial improvement of cerebellar ataxia and brainstem dysfunction. In one patient with a coexisting occipital infarct, the cerebellar ataxia resolved within four weeks, but the patient still had hemianopsia and difficulties in visuospatial orientation. One month after stroke, two patients with multiple supratentorial and infratentorial infarcts still had residual hemiparesis and gait difficulties, but no signs of cerebellar ataxia.

\section{Discussion}

Our findings suggest that 1PICA territory infarction is probably not as rare as previously assumed. In 1936 Goodhart and Davison ${ }^{1}$ reported a pathological finding (case 4). In a necropsy series of 15 cases of infarct limited to the PICA territory, Amarenco et al ${ }^{2}$ found five cases with selective involvement of the lateral branch territory within the cerebellum. Symptoms in two patients were masked by associated supratentorial infarcts and in the other three patients 1PICA infarct was an incidental necropsy finding, so that no clinical correlation could be made. In 13 additional cases of PICA territory infarcts associated with multiple cerebellar infarcts, selective 
involvement of the lateral branch was not reported. Recently Amarenco et al described a patient with a transient infarct in the 1PICA territory that evolved to infarction in the full territory of the PICA after five days. The clinical presentation included acute vertigo, vomiting, unsteadiness, and dysmetria. ${ }^{3}$ In our series of 10 patients, only three had an isolated infarct in the 1PICA territory. All other patients had associated infarcts that partially or completely masked the clinical manifestations of inferolateral cerebellar involvement, mainly in the four patients with a coexisting brainstem infarct, who had prominent signs of cranial nerve and long tract dysfunction. This probably explains why 1PICA territory infarcts have not been recognised clinically yet. They are regularly overlooked on CT and the advent of MRI may allow this type of cerebellar infarct to be recognised more often. We suggest that 1PICA territory infarcts may indeed be as common as those involving the territory of the medial branch of the PICA or the whole PICA territory.

All three patients with isolated 1PICA territory infarct were only moderately ill at onset and developed a pure "hemispheric" cerebellar dysfunction with unsteadiness, and ipsilateral dysmetria and dysdiadochokinesia involving arms and legs to the same extent. Also, two patients had a moderate ipsilateral body sway when standing or walking. None of these three patients had eye movement disturbances or dysarthria. They had a good neurological outcome, with complete regression of cerebellar dysfunction, and persistent disability in the other patients seemed mainly related to coexisting brainstem infarct(s).

In its pure form, the clinical syndrome of 1PICA territory infarct may well be distinguished from neurological dysfunction due to other cerebellar infarcts. Compared with infarcts involving the whole PICA territory or the medial branch of PICA territory, 1PICA territory infarcts do not provoke a vestibular type of dysfunction with acute rotatory vertigo, primary position nystagmus, or truncal ataxia. $^{2910}$ As the lateral branch does not participate in the supply to the dorsal medullar territory, its occlusion never results in medullary infarction. Also, contrary to AICA territory infarcts, isolated 1PICA territory infarcts are not associated with signs of lateropontine involvement. ${ }^{412}$ Finally, 1PICA territory infarcts do not produce dysarthria, which is one of the leading manifestations of SCA territory infarcts. ${ }^{13-15}$

Our findings emphasise that, unlike other cerebellar infarcts, 1PICA territory infarcts are characterised by isolated signs of hemispheric cerebellar dysfunction. This is in accordance with the purely hemispheric territory of the lower cerebellum which is supplied by the 1PICA. Large artery atherosclerosis may be a more common aetiology than in other cerebellar infarcts.

1 Goodhart SP, Davison C. Syndrome of the posterior inferior and anterior inferior cerebellar arteries and their branches. Archives of Neurology and Psychiatry 1936;35: 501-24.

2 Amarenco P, Hauw JJ, Hénin D, Duyckaerts P, Roullet E, Laplane $\mathrm{D}$, et al. Les infarctus du territoire de l'artère cérébelleuse postéro-inférieure. Etude clinico-pathologique de 28 cas. Rev Neurol (Paris) 1989;145:277-86.

3 Amarenco P, Hauw JJ, Caplan LR. Cerebellar infarctions. In: Lechtenberg R, ed. Handbook of cerebellar diseases. In: Lechtenberg R, ed. Handbook of cerebellar

4 Bogousslavsky J, Van Melle G, Regli F, for the Lausanne Stroke Registry Group The Lausanne stroke registry: analysis of 1,000 consecutive patients with first stroke. Stroke 1988;19:1083-92.

Amarenco $P$, Hauw J. Anatomie des artères cérébelleuses. Rev Neurol (Paris) 1989;145:267-76.

6 Lazorthes G. Vascularisation et circulation cérébrale. Paris: Masson, 1961

7 Takahashi $M$, Wilson G, Hanafee W. The anterior inferior cerebellar artery: its radiographic anatomy and significance in the diagnosis of extra-axial tumors of the posterior fossa. Radiology 1968;90:281-7.

8 Morin G. Mécanismes cérébelleux et rôle du cervelet. In: Physiologie du Systeme Nerveux Central, 6th ed. Paris: Masson, 1979:133-57.

9 Duncan GW, Parker SW, Fisher CM. Acute cerebellar infarction in the PICA territory. Arch Neurol 1975;32: 364-8.

10 Amarenco P, Roullet E, Hommel M, Chaine P, Marteau $R$. Infarction in the territory of the medial branch of the posterior inferior cerebellar artery. $\mathcal{F}$ Neurol Neurosurg Psychiatry 1990;53:731-5.

11 Adams RD. Occlusion of anterior inferior cerebellar artery. Archives of Neurology and Psychiatry 1943;49:765-70.

12 Amarenco P, Hauw JJ. Cerebellar infarction in the territory of the anterior and inferior cerebellar artery. A clinico-pathological study of 20 cases. Brain 1990;113: 139-55.

13 Lechtenberg R, Gilman S. Speech disorders in cerebellar disease. Ann Neurol 1978;3:285-90.

14 Amarenco $P$, Hauw J. Cerebellar infarction in the territory of the superior cerebellar artery. A clinicopathoterritory of the superior cerebellar artery. A clinicopatho-

15 Struck LK, Biller J, Bruno A, Neiman RF, Loftus CM, Yuh WT, et al. Superior cerebellar artery territory infarction. Cerebrovascular Diseases 1991;1:71-5. 